\title{
Sexually transmitted diseases in transient British forces in the tropics
}

\author{
E J Adams, P W Strike, A D Green, R G Masterton
}

\begin{abstract}
Objective-To compare the incidence of sexually transmitted diseases (STD) in British troops in the tropics with that in a standard population.

Design-Retrospective analysis of STD clinic records over one calendar year. Setting-A British Military Hospital in the Tropics serving 1441 resident personnel.

Subjects-All patients attending a STD clinic.

Main Findings -815 cases of STD were recorded during the study period, giving incidence rate of 56558 per 100000 population per year. When compared with a matched population from England and Wales, the age standardised relative risk for STD amongst tropical troops was $25 \cdot 0$ (95\% confidence interval $24 \cdot 9$ to $25 \cdot 1$ ). Thirty nine percent of cases reported prostitute contact as a source of their disease. Of patients questioned about condom usage, $70 \%$ reported that they did not normally use a condom.

Conclusions-British troops spending short periods of time in a tropical environment are significantly more likely to acquire a STD than men in the same age groups in England and Wales. The proportions of cases who reported that they did not use condoms and the number who cited prostitute contact as a source of infection indicate that even greater sexual education of troops on deployment overseas may be required.
\end{abstract}

(Genitourin Med 1994;70:94-96)

\section{Introduction}

Although military personnel have generally been regarded as a high risk group for sexually transmitted diseases (STD) a recent study in a stable European British Force showed a pattern and incidence of STD comparable to the civilian population of the United Kingdom. ${ }^{1}$ We now report a companion study involving transient groups of British military personnel serving in a tropical environment.

\section{Patients and methods}

Records from a STD clinic at a British Military Hospital in a tropical area for a one year period were analysed retrospectively. The patients were drawn from a resident military population of 1441 personnel, for which demographic details were obtained for the calendar year in which most of the study took place ("The Study Year").

The male England and Wales population in the study year was taken as the standard population for the purposes of comparison. The data for STD surveillance for the standard population were provided by the Public Health Laboratory Service Communicable Disease Surveillance Centre, and were taken from reports from genitourinary medicine Clinics for males in England and Wales aged 16 to 59 years in the study year. No information regarding the probable source of infection was available for the latter, so that in this instance only a comparison with 1983 figures $^{1}$ for British troops serving in Northern Europe was made.

For three months at the end of the study year a prospective investigation of condom usage was performed.

The age-standardized rate of STD in the military population was estimated using the indirect method described in detail by Armitage. ${ }^{2}$ In simple terms the STD incidence of the study population was expressed relative to that of the standard population (males in England and Wales) by the ratio of observed to expected cases, which is termed here the standardised incidence ratio.

\section{Results}

Tables 1 and 2 respectively show comparisons between the composition and age distribution of the standard and study populations. STD cases are shown in table 3. Non-specific genital infection (NSGI) and gonorrhoea accounted for $45 \%$ of all cases.

The age standardised relative risk for STD amongst tropical troops was $25 \cdot 0$ (95\% confidence interval $24 \cdot 9$ to $25 \cdot 1$ )

Table 4 shows a comparison of the declared source of each case. Condom

Table 1 Comparison of the characteristics of the study and standard populations in the study year

\begin{tabular}{lll}
\hline & $\begin{array}{l}\text { Study group } \\
(\%)\end{array}$ & $\begin{array}{l}\text { England and Wales } \\
\text { Population (\%) }\end{array}$ \\
\hline $\begin{array}{l}\text { Proportion females } \\
\begin{array}{l}\text { Proportion of males } \\
\text { married }\end{array}\end{array}$ & 0.4 & $51 \cdot 3$ \\
$\begin{array}{l}\text { Proportion of personnel } \\
\text { accompanied by spouse }\end{array}$ & 55.0 & 48.0 \\
\hline
\end{tabular}

Source: see Patients and Methods.
R G Masterton

Address correspondence to Accepted for publication 30 November 1993 
Table 2 Comparison of male age distributions in the study and standard populations in the study year

\begin{tabular}{lcll}
\hline & Study Group (\%) & $\begin{array}{l}\text { England and Wales } \\
\text { Proportion of total } \\
\text { Population (\%) }\end{array}$ & $\begin{array}{l}\text { Proportion of 16-54 } \\
\text { years population } \\
(\%)\end{array}$ \\
\hline $16-19$ & $3 \cdot 1$ & $6 \cdot 4$ & $11 \cdot 4$ \\
$20-24$ & $32 \cdot 5$ & $8 \cdot 6$ & $15 \cdot 4$ \\
$25-29$ & $36 \cdot 5$ & $8 \cdot 2$ & $14 \cdot 7$ \\
$30-34$ & $16 \cdot 0$ & $7 \cdot 1$ & $12 \cdot 7$ \\
$35-39$ & $6 \cdot 3$ & $7 \cdot 0$ & $12 \cdot 5$ \\
$40-44$ & $3 \cdot 8$ & $7 \cdot 3$ & $13 \cdot 1$ \\
$45-49$ & $1 \cdot 4$ & $5 \cdot 8$ & $10 \cdot 4$ \\
$50-54$ & $0 \cdot 4$ & $5 \cdot 5$ & $9 \cdot 4$ \\
$55-59$ & $0 \cdot 0$ & $5 \cdot 3$ & 0.0 \\
\hline
\end{tabular}

Source: see Patients and Methods.

Table 3 STD cases recorded in study population

\begin{tabular}{lcc}
\hline & Study Group \\
\cline { 2 - 3 } & & \\
\cline { 2 - 3 } & No cases & $\begin{array}{c}\text { Incidence rate } \\
100 \text { 000/year }\end{array}$ \\
\hline Syphilis & 5 & 347 \\
Gonorrhoea & 128 & 8,883 \\
Chancroid & 28 & 1,943 \\
LGV & 4 & 278 \\
NSGI & 219 & 15,199 \\
Candida & 11 & 7,703 \\
Pubic Lice & 27 & 1,874 \\
Herpes Simplex & 22 & 1,527 \\
Genital Warts & 62 & 4,303 \\
Other conditions requiring treatment & 61 & 4,233 \\
Other conditions not requiring treatment & 148 & 10,271 \\
Total STD & 815 & 56,558 \\
\hline
\end{tabular}

Study population $n=1,441$. practices are reported in table 5. Figure 1 shows the time of presentation of cases from arrival in the tropics for patients with a known posting duration of 6 months.

\section{Discussion}

This study is qualified by its reliance on retrospective case record analysis which precludes standardisation or verification of diagnoses and case histories. However, the clinic was manned at all times by trained personnel and it was the only English speaking clinic to which patients had access. We therefore believe that a broadly accurate picture is given of the pattern and incidence of STD in the study population.

The earlier reports showing military personnel to be a high risk group for STD were based on studies of venereal diseases in male Service personnel during wars. ${ }^{3}$ The only study of British military forces in the tropics since 1945 looked at Army servicemen in Singapore in 1970 and showed syphilis to be fifty times commoner in that group than in UK males. ${ }^{4}$ Demographic details, including duration in the area, were not recorded. As neither of these studies involved age matched comparisons, no relative risk has previously been ascertained.

We have demonstrated that servicemen in the study group were 25 times more likely to acquire STD than men in England and Wales. This figure is broadly in agreement with the crude factor reported from Singapore. Schofield showed that STD amongst seamen is most commonly acquired in their home country rather than when travelling. ${ }^{5}$ Fulford et al found neither prolonged residence nor employment in the tropics to be associated with an increased risk of STD. ${ }^{6}$ Our findings are at variance with these reports which were based on clinic attenders in the United Kingdom.

The 1983 European study showed that the Table 5 Condom usage of 140 consecutive male clinic attenders (three months at the end of study year)

\begin{tabular}{lll}
\hline & Used condom & No condom used \\
\hline All sexual contacts & $30 \%$ & $70 \%$ \\
Prostitutes & $31 \%$ & $69 \%$ \\
\hline
\end{tabular}

Time of presentation of cases after arrival in tropics.

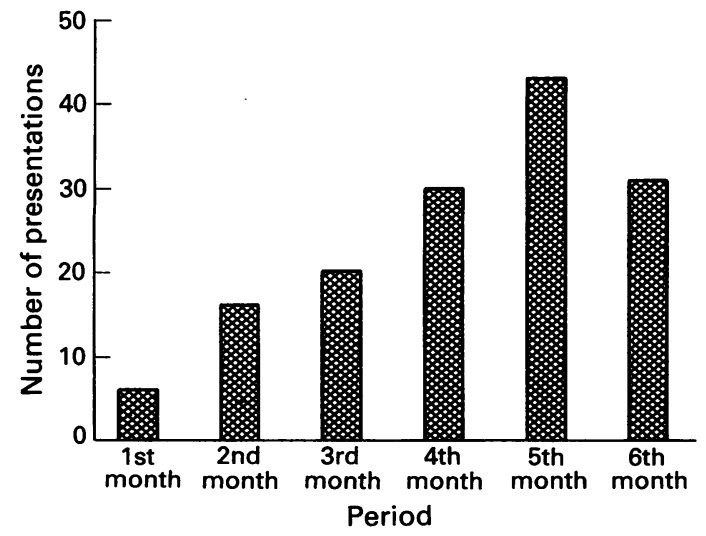
regular sexual partner was the commonest source of STD in servicemen. In that study prostitute-acquired disease mirrored reported UK data and was never greater than $11 \% .^{1}$ However, prostitutes accounted for $65 \%$ of STD in combatant Australian troops in Vietnam $^{7}$ and Thin commented on British Army patients in Singapore that "usually the primary contact was a local prostitute". Although the pattern and spectrum of STD seen in the study and standard populations were broadly similar, certain notable exceptions predictably associated with tropical areas were found. These included lymphogranuloma venereum, chancroid and candidiasis. The much higher rate of STD observed in the study population suggests both an increased number of sexual encounters and an increased use of prostitutes. The latter was confirmed with prostitute-acquired disease running at approximately five times the rate in British forces stationed in Europe. These findings suggest that the sexual attitudes and behaviour of the study group, which is a cohort selected only by posting to a 
tropical area, may be different from those of their counterparts in Europe.

This study did not specifically look for risk factors responsible for the observed rate of STD nor for indications of sexual activity. However, a number of potential influences were identified. The military population was almost exclusively male and "single" in the sense that a vast majority were separated from their regular partner for a significant period of time. The servicemen did not have ready access to the European women with whom they would normally form stable relationships. Finally, the age distribution of the study group was shifted from the standard population with the predominance of younger males possibly affecting the sexual behaviour of the group as a whole.

Given this study's results, the low condom use rate during sexual exposure is disappointing; particularly so is the finding that it was unaltered when the contact was a prostitute. This contrasts with studies in Edinburgh carried out in 1988 in which $62 \%$ of female prostitutes reported that they always used condoms. ${ }^{8}$ Health education lectures, includ- ing STD briefings on risks and preventative action, form part of the arrival talks given to the study group. Figure 1, which shows increasing numbers of cases over the first months in the area, indicates that education should be reinforced at regular intervals.

We are grateful to the Director General of Medical Services, Royal Air Force, for permission to publish this paper and to Lieutenant Colonel Rao and Sergeant Stoker, without whose enthusiastic help this project would not have been possible.

1 Masterton RG, Strike PW. Sexually transmitted diseases in a British military force in peacetime Europe, 1970-83. Genitourin Med 1988;64:54-8.

2 Armitage P. Statistical Methods in Medical Research London: Blackwell 1974.

3 Adler MW. The terrible peril: a historical perspective on the venereal diseases. $B M \mathcal{F}$ 1980;281:206-11.

4 Thin RNT. Venereology in the British Army in Singapore in 1970. Br $\mathcal{F}$ Venereal Dis 1972;48:542-4.

5 Schofield CBS. Difficulties in the management of venereal diseases in mariners. WHO Bulletin 1965;33:867-80

6 Fulford KWM, Catterall RD, Hornville E, Lum KS Wilson GD. Social and psychological factors in the distribution of STD in male clinic attenders. I Demographic and social factors. $\operatorname{Br} \mathcal{f}$ Venereal Dis 1983;59. 376-80.

7 Hart G. Factors influencing venereal infection in a war environment. Br $\mathcal{F}$ Venereal Dis 1974;50:68-72.

8 Thomas RM, Plant MA, Plant ML, Sales DI. Risks of AIDS among workers in the "sex industry": some initial results from a Scottish study. BMY 1989;299:148-9. 